\title{
Crop Insurance Policies Available to Blueberry Growers in Florida ${ }^{1}$
}

\author{
Robert Ranieri and Ariel Singerman ${ }^{2}$
}

Production risk is one of the main risks that growers are subject to. Unlike in manufacturing, a grower can combine the same inputs every year and yet obtain different yields each time. The main source of risk and, therefore, the extent to which yields may differ from year to year in crop production stems from the unpredictable nature of weather, pests, diseases, etc. Figure 1 illustrates the indemnities (in percent) for all insured crops in Florida by cause of loss during 2016/17.

Another source of risk for growers is market or price risk. Since growers are typically price takers, they are exposed to the (supply and demand) forces of markets for inputs and outputs. Thus, commodity prices vary each year and even within a given season. In addition, growers seldom know for certain the prices of farm inputs and outputs at the time they must make decisions about how much inputs to use or how much output to produce. Therefore, market risk includes risks derived from cyclical and seasonal price fluctuations of agricultural products, trade restrictions (market access), subsidies, and currency exchange rates. Contracts with buyers and suppliers can mitigate market risk but when selling a commodity, contracts can also limit a price increase that would benefit the grower.

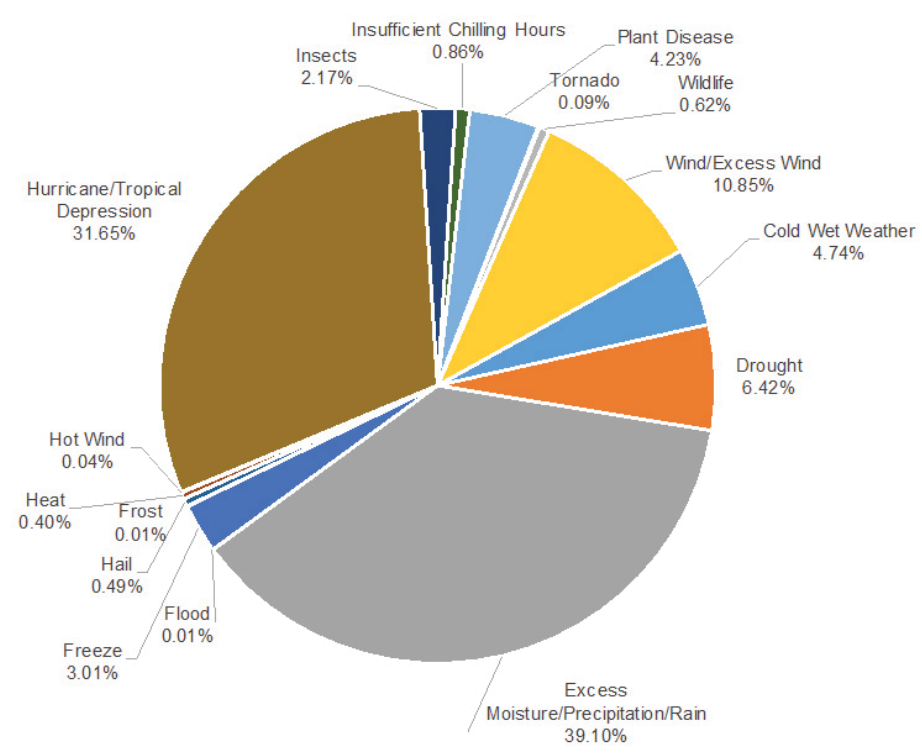

Figure 1. Indemnities (in Percentage) by Cause of Loss for All Insured Crops in Florida during 2016/17

Credits: Risk Management Agency, authors' calculations

\section{Crop Insurance as a Tool for Managing Risk}

Growers can purchase different types of crop insurance to manage risk; policies will cover either production or revenue losses. However, regardless of the policy choice, by purchasing crop insurance the grower transfers part of the risk to an insurance company in exchange for paying a premium (which is the cost of purchasing crop insurance).

1. This document is FE1054, one of a series of the Food and Resource Economics Department, UF/IFAS Extension. Original publication date April 2019. Visit the EDIS website at https://edis.ifas.ufl.edu for the currently supported version of this publication.

2. Robert Ranieri graduate student; and Ariel Singerman assistant professor; Food and Resource Economics Department, UF/IFAS Citrus Research and Education Center, Lake Alfred, FL 33850 
At the time of enrollment, the grower chooses a certain level of coverage, which in turn determines two components within the policy. First, it determines the guarantee or liability (the amount at which the grower is insuring for). And, second, the coverage level chosen determines the deductible (the amount of loss for which the grower will receive no indemnity). In the event of a loss, any below the guarantee will trigger a payment to the grower (indemnity). Figure 2 illustrates the basics of how crop insurance works with a one-acre example. Assume the grower expects revenue to be $\$ 10,295$ and chooses a $65 \%$ coverage level. This choice of coverage level sets the guarantee at $\$ 6,692$ and also establishes the premium the grower will pay for insuring at such level. If the grower experiences a $50 \%$ loss, the actual farm revenue will be $\$ 5,147$. In this example, the indemnity will be equal to $\$ 1,545$, which is the difference between the guarantee and the actual farm revenue. There will be no indemnity for the difference between $\$ 10,295$ and $\$ 6,692$ because that amount is the deductible.

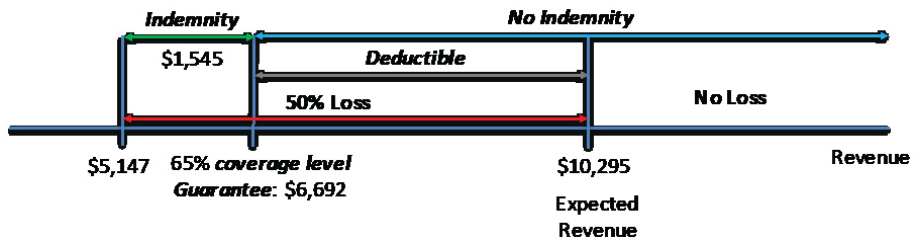

Figure 2. Illustration of the basic concepts involved in crop insurance.

Figure 3 extends the example described above by illustrating the difference in revenue when insuring versus not insuring. The small difference in revenue between the green and blue lines in Figure 3-which denote the cases of insuring and not insuring, respectively-is the policy premium. Figure 3 illustrates the key role of crop insurance in mitigating risk; when purchasing insurance, despite any potential loss in farm revenue, total revenue does not fall below the floor established by guarantee. This is so because if a loss greater than the guarantee $(\$ 6,692)$ occurs, an indemnity is triggered; limiting downside risk (because the risk was transferred from the grower to the insurance company). On the contrary, when not purchasing crop insurance, the grower's total revenue will be equal to the farming revenue; in other words, the grower will have to face all losses.

\section{Federal Crop Insurance Programs}

The US Department of Agriculture (USDA) Risk Management Agency (RMA) acts on behalf of the Federal Crop Insurance Corporation (FCIC) to administer all federal crop insurance programs. The RMA designates private insurance companies as Approved Insurance Providers (AIPs). AIPs enter into a reinsurance agreement that establishes cooperative financial assistance between FCIC and the insurance companies. In addition, AIPs market, underwrite, and adjust claims for crop insurance policies and transmit policy information to FCIC.

To market crop insurance products, AIPs contract independent licensed agents who provide product and premium information to growers, collect data from them, and get a commission. It is important to realize that premium rates and insurance terms and conditions are established by FCIC. Therefore, the premium for a specific policy and coverage level will be the same across companies and agents; companies and agents compete with their knowledge, customer service, and related insurance products.

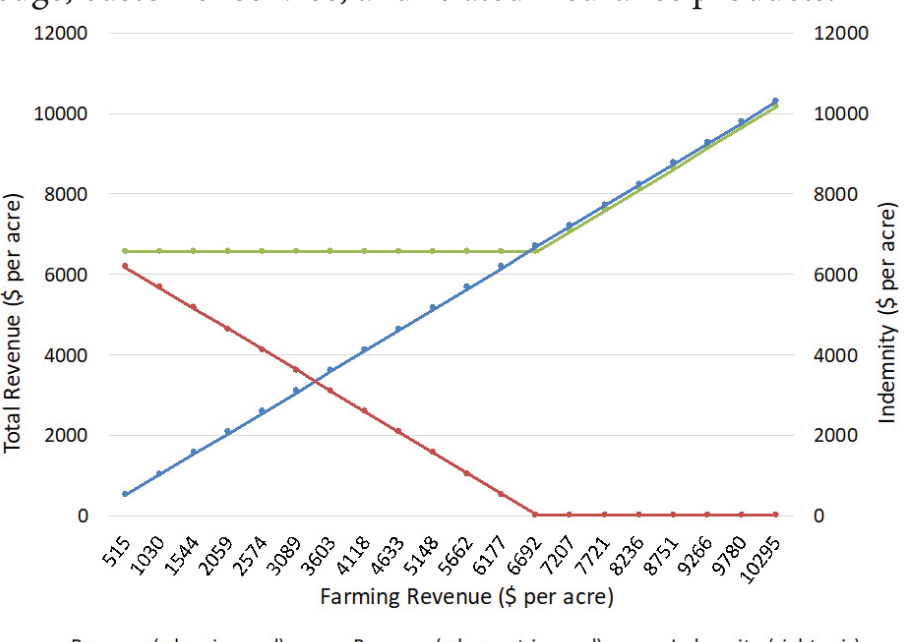

$\rightarrow$ Revenue (when insured) $\rightarrow$-Revenue (when not insured) $\rightarrow$-Indemnity (right axis)

Figure 3. Illustration of the difference in revenue when insuring versus not insuring.

\section{Crop Insurance Policies for Blueberries}

The two main crop insurance policies available for blueberry growers are Actual Production History (APH) and Whole Farm Revenue Protection (WFRP). The fundamental difference between the two policies is that while the former provides coverage against losses in production, the latter provides coverage against losses in revenue.

APH is a multiple peril crop insurance policy that provides protection against a decrease in yields due to causes of loss such as adverse weather conditions; failure of irrigation water supply (if caused by an insured peril); fire; insects or plant disease; insufficient chilling hours; and wildlife. Actual Production History (APH) is a policy based on the insured farm's records, and eligibility requirements include growing Highbush or Rabbiteye varieties with production of at least 1,000 lbs. per acre in at least 1 of 3 previous crop years.

At the time of sign up, the grower chooses the coverage level. Coverage levels range from 50 to $75 \%$ (in 5\% 
increments) of the approved farm yield. The grower also needs to choose the percent price coverage level. Those levels range from 55 to $100 \%$ (in 5\% increments) of the annual RMA-established crop price. APH coverage can be augmented to $86 \%$ with the Supplemental Coverage Option (SCO), which is only available as additional coverage to $\mathrm{APH}$ and not as a stand-alone policy. Catastrophic Risk Protection (CAT) is another policy available to blueberry growers; it is based on APH and provides coverage at 50\% of the approved yield and 55\% of the price election. CAT coverage is $100 \%$ subsidized but has an administrative fee of $\$ 300$ per crop per county (regardless of acreage).

APH coverage period begins on November 21 for new policies or September 16 for existing policies. Eligible counties for insuring blueberry under this policy are Alachua, Citrus, De Soto, Hardee, Hernando, Highlands, Hillsborough, Lake, Marion, Orange, Pasco, Polk, Putnam, and Sumter. Growers in counties other than those listed above may submit a written agreement request through a crop insurance agent.

Crop insurance premiums are subsidized by the federal government. The rationale for subsidies is to incentivize growers' participation so as to decrease ad-hoc financial relief when a natural disaster strikes. The subsidy rates vary by insurance plan and coverage level; they decrease for higher levels of coverage. For APH policies, the subsidy schedule for different levels of coverage is shown in table 1. Thus, for example, if the grower chooses the 75-percent coverage level, the grower's premium share would be 45 percent of the total premium.

Table 2 illustrates an example of APH coverage for one acre planted with blueberries in Hardee county. Assume the approved yield (average of the APH yields) is 4,118 lbs/acre and that the grower chooses $65 \%$ coverage. The production guarantee is then 2,677 lbs/acre. Further assume that the growers' price election (price per pound used to determine premium and indemnity) is $\$ 2.50$ per $\mathrm{lb}$. Liability is then established at $\$ 6,692$, and the deductible is $\$ 3,603$. The base premium rate established by RMA in this case given the information above is 0.045 . Therefore, the total premium is $\$ 301$. Since the federal premium subsidy for $65 \%$ coverage is $59 \%$, the grower premium in this example is $\$ 123$. Suppose the grower suffers an $80 \%$ loss in yield due to an insurable cause of loss. The estimated loss is $\$ 8,236$, and the indemnity the grower will receive is $\$ 4,633$.

WFRP is a policy for all commodities on the farm. It provides coverage against losses in farm revenue (not in the underlying commodity). In other words, all farm revenue is insured together under one policy, and individual commodity losses are not considered. The approved revenue amount under this policy is the lower of (1) historic farm revenue (5-year average based on tax records), or (2) expected revenue. Coverage level ranges from 50 to $85 \%$ (in 5\% increments). Eligibility criteria include having no more than $\$ 1$ million expected revenue from animals and animal products and having no more than $\$ 1$ million from greenhouse and nursery products. WFRP is available for any farm with up to $\$ 8.5$ million in insured (i.e., approved) revenue. The annual sales closing date is February $28^{\text {th }}$.

Under WFRP, the premium subsidy depends on how diversified the farm is. If only one commodity is grown on the farm, then the basic premium subsidy applies. If two or more commodities are grown on the farm, the premium subsidy increases to $80 \%$ as illustrated in Table 3. However, each commodity grown on the farm needs to make a minimum contribution to revenue (in percentage terms) for the additional premium subsidy to apply. In case two commodities are grown on the farm, each commodity needs to contribute at least $16.67 \%$ to the farm's revenue; that percentage is $11.11 \%$ if three commodities are grown on the farm, $8.33 \%$ if it is four commodities, and $6.67 \%$ if it is five commodities. In addition, the WFRP premium rate also depends on farm diversification; RMA establishes a lower premium rate for higher diversification (up to 7 commodities).

Table 4 illustrates an example of WFRP coverage for one acre in Hardee county. Assume that the farm revenue has been $\$ 10,295$ in each of the last five years so that the 5-year average historic farm revenue is also $\$ 10,295$. Also assume that the expected revenue next year will be $\$ 11,000$. Thus, the approved revenue will be $\$ 10,295$ (the lowest of the historic farm revenue and the expected revenue). Also assume that the grower chooses $65 \%$ coverage, so that (just as in the APH example) the liability is then established at $\$ 6,692$, and the deductible is $\$ 3,603$.

Continuing with the previous example illustrated in Table 4 , the base premium rate established by RMA given the information above for a farm growing only blueberries is 0.111 . Therefore, the total premium is $\$ 743$, the premium subsidy is $59 \%$, and the grower's premium is $\$ 305$. However, if $74 \%$ of the farm's revenue is generated from growing blueberries and the remainder from citrus-so that two commodities are grown on the farm-then the commodity rate increases slightly, but the diversity factor decreases the premium rate to 0.741 . Therefore, the total premium is $\$ 560$. Since the federal premium subsidy is $80 \%$, the premium the grower needs to pay is $\$ 112$. If the number 
of commodities grown on the farm is three, so that $74 \%$ of the farm's revenue is generated from growing blueberries and $26 \%$ from two different citrus commodities (13\% each), the diversity factor decreases the premium rate to 0.709 . Therefore, the total premium is $\$ 536$. The federal premium subsidy is $80 \%$ and the grower's premium is $\$ 107$.

Assuming the grower suffers an $80 \%$ loss in farm revenue due to an insurable cause of loss. The estimated loss is $\$ 8,236$, and the indemnity the grower will receive is $\$ 4,633$. Despite the fact that we made the numerical examples for APH and WFRP as similar as possible to highlight the differences in calculations between the two policies, it is key to understand that the coverage that each policy offers is different. APH offers coverage against a loss in a farm's production, whereas WFRP offers coverage against a loss in a farm's revenue. Under APH, the price is established by RMA, whereas under WFRP, price is irrelevant; it is the decrease in revenue that matters.

Another important difference between both policies is their stance on abandoned acres. In 2016, warmer-than-normal weather in Florida resulted in low chill hour accumulation for blueberries, which delayed harvest and caused many growers to miss the premium prices they can typically obtain in the market. Therefore, many growers were better off leaving their crop unharvested. Insufficient chill hours are an insurable cause of loss under APH, but the unharvested crop was not considered a loss under such policy. Contrastingly, under WFRP, when market prices do not cover the cost of production, the unharvested crop is not considered abandoned and, therefore, can trigger an indemnity.

\section{Bearing Risk: Choosing the Right Coverage Level}

Risk management does not mean eliminating all risk, rather limiting it to a level that the grower is willing to bear. Like people in general, growers vary greatly in their willingness to take risks. Therefore, the level of risk a grower should accept is an individual decision based on personal preferences. Most people, growers included, are risk averse (avoiders). Risk-averse people prefer a low variability of outcomes and, therefore, are willing to pay some amount of money to reduce the risk they are subject to (for example by purchasing an insurance policy). Thus, a risk-averse person is willing to forgo some expected return in exchange for a reduction in outcome variability. The trade-off depends on how risk averse the individual is.

Due to the role of personal risk preferences in growers' choices to bear risk, an analysis of risky outcomes does not necessarily yield a preferred choice, as in "one size fits all." The grower should weigh the possible options along with personal risk preferences to make the right insurance policy choice for him.

\section{Conclusions}

The Federal Crop Insurance Program allows blueberry growers to purchase coverage for production or revenue losses with subsidized premiums. The 2014 Farm Bill continued the trend towards enhancing insurance coverage for specialty crops; the development of WFRP policy illustrates such efforts. WFRP allows growers to insure their farm revenue under one policy. As illustrated in this publication, the premium for WFRP can be comparable to that for APH, depending, for example, on the number of commodities grown in the farm.

Even though CAT may still be the cheapest option for many growers in Florida, such a policy may not be the most advantageous from a risk-management perspective. In many cases, growers across the state may be choosing CAT just to make themselves eligible for ad-hoc hurricane relief. But the coverage CAT offers is very limited; losses need to be greater than $50 \%$ to trigger an indemnity, and even then the price that will be used to price their loss will be $55 \%$ of that established by RMA. WFRP might offer growers of high-value specialty crops a higher level of coverage for a premium that they might be willing to pay.

\section{Useful Resources}

USDA-Risk Management Agency fact sheet on APH for blueberries in Florida: https://www.rma.usda.gov/ en/Fact-Sheets/Valdosta-Regional-Office-Fact-Sheets/ Blueberries-2018-AL-FL-GA-SC

USDA-Risk Management Agency fact sheet on WFRP: https://www.rma.usda. gov/Fact-Sheets/National-Fact-Sheets/ Whole-Farm-Revenue-Protection-2018

USDA-Risk Management Agency cost estimator: https:// ewebapp.rma.usda.gov/apps/costestimator/ 
Table 1. Premium Subsidy for Each Level of APH Coverage

\begin{tabular}{|c|c|c|c|c|c|c|}
\hline & \multicolumn{5}{|c|}{ Coverage Level } \\
\cline { 2 - 6 } & $50 \%$ & $55 \%$ & $60 \%$ & $65 \%$ & $70 \%$ & $75 \%$ \\
\hline Premium Subsidy & $67 \%$ & $64 \%$ & $64 \%$ & $59 \%$ & $59 \%$ & $55 \%$ \\
\hline Grower's Premium Share & $33 \%$ & $36 \%$ & $36 \%$ & $41 \%$ & $41 \%$ & $45 \%$ \\
\hline
\end{tabular}

Table 2. APH Blueberry Coverage Example for One acre in Hardee County

\begin{tabular}{|c|c|c|}
\hline Line \# & RMA Terminology & Amount \\
\hline (1) & Approved yield (Ibs./acre) & 4,118 \\
\hline$(2)$ & Coverage level & $65 \%$ \\
\hline (3) & Guarantee (lbs./acre) (1) x (2) & 2,677 \\
\hline (4) & Price election (established by RMA) & $\$ 2.50$ \\
\hline (5) & Liability (3) x (4) & $\$ 6,692$ \\
\hline (6) & Deductible $[(1)-(3)] \times(4)$ & $\$ 3,603$ \\
\hline \multicolumn{3}{|c|}{ Base Premium } \\
\hline (7) & Premium rate & 0.045 \\
\hline (8) & Total premium $(5) \times(7)$ & $\$ 301$ \\
\hline (9) & Subsidy percent & $59 \%$ \\
\hline$(10)$ & Subsidized amount (8)x(9) & $\$ 178$ \\
\hline (11) & Grower premium (8)-(10) & $\$ 123$ \\
\hline \multicolumn{3}{|c|}{ Indemnity } \\
\hline$(12)$ & Assumed production loss & $80 \%$ \\
\hline (13) & Loss value (1) x (4) x (12) & $\$ 8,236$ \\
\hline$(14)$ & Indemnity (13) - (6) & $\$ 4,633$ \\
\hline
\end{tabular}

Table 3. Premium Subsidy for Each Level of WFRP Coverage and Number of Commodities Grown on the Farm

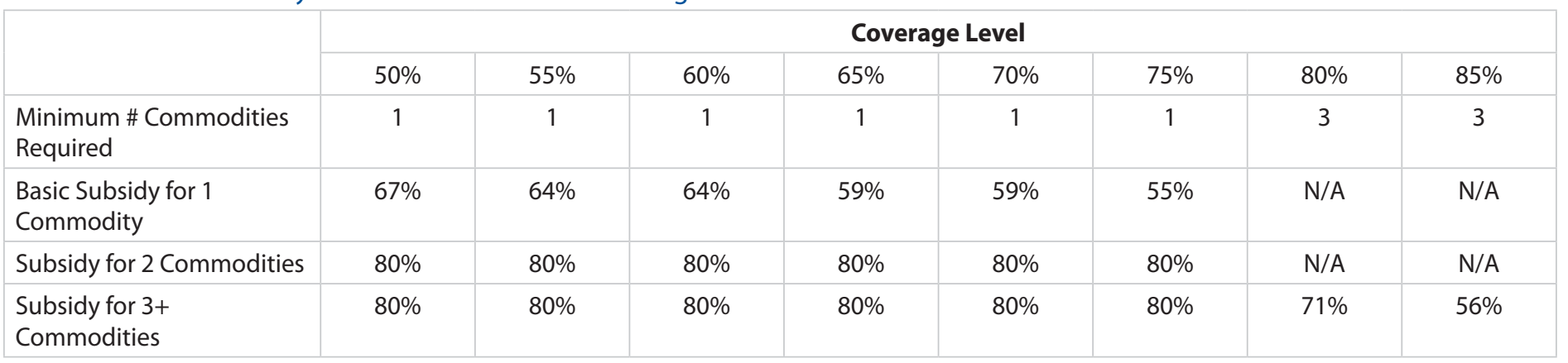


Table 4. WFRP Blueberry Coverage Example for One acre in Hardee County

\begin{tabular}{|c|c|c|c|c|c|c|}
\hline$(1)$ & Allowable revenue* & $\begin{array}{l}\text { Year } 1 \\
\$ 10,295\end{array}$ & $\begin{array}{c}\text { Year } 2 \\
\$ 10,295\end{array}$ & $\begin{array}{l}\text { Year } 3 \\
\$ 10,295\end{array}$ & $\begin{array}{l}\text { Year } 4 \\
\$ 10,295\end{array}$ & $\begin{array}{c}\text { Year } 5 \\
\$ 10,295\end{array}$ \\
\hline$(2)$ & Average & \multicolumn{5}{|l|}{$\$ 10,295$} \\
\hline (3) & Expected revenue & \multicolumn{5}{|l|}{$\$ 11,000$} \\
\hline$(4)$ & Approved revenue $[\min ((2),(3))]$ & \multicolumn{5}{|l|}{$\$ 10,295$} \\
\hline$(5)$ & Coverage level & \multicolumn{5}{|l|}{$65 \%$} \\
\hline$(6)$ & Guarantee $[(4) x(5)]$ & \multicolumn{5}{|l|}{$\$ 6,692$} \\
\hline$(7)$ & Deductible & \multicolumn{5}{|l|}{$\$ 3,603$} \\
\hline \multicolumn{7}{|c|}{ Base Premium Calculation } \\
\hline & & BB Only & $\begin{array}{c}\text { BB } 74 \% \text { and } \\
\text { citrus } 26 \%\end{array}$ & $\begin{array}{l}\text { BB } 75 \% \text { and } \\
\text { citrus } 2 \times 13 \%\end{array}$ & & \\
\hline (8) & Commodity rate & 0.111 & 0.113 & 0.113 & & \\
\hline (9) & Commodity factor & 1 & 1 & 1 & & \\
\hline (10) & Diversity factor & 1 & 0.741 & 0.709 & & \\
\hline$(11)$ & Premium rate $[(8) \times(10)]$ & 0.111 & 0.084 & 0.080 & & \\
\hline$(12)$ & Total premium $[(6) \times(11)]$ & $\$ 743$ & $\$ 560$ & $\$ 536$ & & \\
\hline (13) & Subsidy percent & $59 \%$ & $80 \%$ & $80 \%$ & & \\
\hline$(14)$ & Subsidized amount [(12)x(13)] & $\$ 438$ & $\$ 448$ & $\$ 429$ & & \\
\hline$(15)$ & Grower premium [(12)-(14)] & $\$ 305$ & $\$ 112$ & $\$ 107$ & & \\
\hline \multicolumn{7}{|c|}{ Indemnity calculation } \\
\hline (16) & Assumed revenue loss & $80 \%$ & & & & \\
\hline$(17)$ & Loss value $[(4) \times(16)]$ & $\$ 8,236$ & & & & \\
\hline$(18)$ & Indemnity [(17)-(7)] & $\$ 4,633$ & & & & \\
\hline
\end{tabular}

